\title{
Modern Rhesus (Rh) typing in transfusion and pregnancy
}

\author{
Willy Albert Flegel MD
}

Cite as: CMAJ 2021 January 25;193:E124. doi: 10.1503/cmaj.201212

\section{1} Patients who are Rhesus (Rh) negative lack the $D$ antigen on their red blood cells

Patients who are Rh negative, if transfused with Rh-positive blood, can become immunized for anti-D immunoglobulin (Ig). ${ }^{1}$ These patients are at risk of severe transfusion reactions, and if they become pregnant, the fetus is at risk of severe anemia. A small number $(0.5 \%)$ of patients have a serologic "weak D" phenotype, and when these patients need a transfusion, providers are left wondering if Rh-negative red blood cells and Rhlg prophylaxis are needed.

2 More than 160 distinct molecular weak $D$ types are known Weak D types are clustered by ethnic origin. Types 1 to 3 are typical in White people, type 4 variants cluster in Black people and type 15 is found most often in East Asian people. Other weak D types are encountered sporadically.

\section{3}

\section{Molecular typing of weak $D$ improves patient safety without increasing costs}

Although the technology for molecular typing has been established for 2 decades, only the serologic test is routinely applied. Molecular typing is reliable, and applying this precision medicine approach can avoid unnecessary therapies, but it must be specially requested in many hospitals. ${ }^{2}$

Patients with the 5 most prevalent weak $D$ types can be safely treated as Rh positive

Patients carrying the molecular weak D types $1,2,3,4.0$ or 4.1 should be treated as Rh positive. ${ }^{3}$ Pregnant women with these weak $D$ phenotypes do not benefit from Rhlg prophylaxis. ${ }^{4}$ They should not be exposed to Rhlg, which is pooled from thousands of immunized donors. This approach conserves the limited supply of Rh-negative blood. ${ }^{5}$

\section{Patients carrying less common molecular weak D types should be treated as $\mathrm{Rh}$ negative}

Less common types include the weak $D$ type 4.2 , though it is more prevalent among people of African descent. ${ }^{6}$ An exhaustive list of weak $D$ types that should be treated as Rh negative is maintained by the International Society of Blood Transfusion. ${ }^{7}$ If providers are unsure about whether types should be treated as Rh positive or negative, an immunohematology reference laboratory should be contacted.

\section{References}

1. Flegel WA, Wagner FF, O'Donghaile DP. Anti-D immunization rates may exceed $50 \%$ in many clinically relevant settings, despite varying widely among patient cohorts. Transfusion 2020;60:1109-10.

2. Kacker S, Vassallo R, Keller MA, et al. Financial implications of RHD genotyping of pregnant women with a serologic weak D phenotype. Transfusion 2015;55:2095-103.

3. Flegel WA, Denomme GA, Queenan JT, et al. It's time to phase out "serologic weak D phenotype" and resolve D types with $R H D$ genotyping including weak D type 4. Transfusion 2020;60:855-9.

4. Fung KFK, Eason E. No. 133-prevention de l'allo-immunisation foeto-maternelle Rh. J Obstet Gynaecol Can 2018;40:e11-21.

5. Barty RL, Pai M, Liu Y, et al. RBCs: Where is universal donor blood being used? Vox Sang 2017;112:336-42.

6. Flegel WA, Denomme GA, Yazer MH. On the complexity of D antigen typing: a handy decision tree in the age of molecular blood group diagnostics. J Obstet Gynaecol Can 2007;29:746-52.

7. Storry JR, Clausen FB, Castilho L, et al. International Society of Blood Transfusion Working Party on Red Cell Immunogenetics and Blood Group Terminology: report of the Dubai, Copenhagen and Toronto meetings. Vox Sang 2019;114:95-102.

\section{Competing interests: None declared.}

This article has been peer reviewed.

Affiliation: NIH Clinical Center, National Institutes of Health, Bethesda, Md.

Funding: The author is supported by the NIH Clinical Center, Intramural Research Program, ID ZIA CL002128.

Disclaimer: The views expressed do not necessarily represent the view of the National Institutes of Health, the Department of Health and Human Services, or the US Federal Government.

Content licence: This is an Open Access article distributed in accordance with the terms of the Creative Commons Attribution (CC BY-NC-ND 4.0) licence, which permits use, distribution and reproduction in any medium, provided that the original publication is properly cited, the use is noncommercial (i.e., research or educational use), and no modifications or adaptations are made. See: https://creativecommons.org/ licenses/by-nc-nd/4.0/

Correspondence to: Willy Flegel, waf@nih.gov 